\title{
MYOCARDIAL PRESERVATION WITH PROPOFOL IS DOSE-DEPENDENT
}

Authors: David M. Ansley MD,FRCPC ${ }^{1}$, Zhiyong Huang, $\mathrm{MD}^{2}$ and Zhengyuan Xia MD,PhD ${ }^{2}$

Institutions: ${ }^{1}$ Department of Anesthesiology, University of British Columbia, Vancouver, Canada and ${ }^{2}$ Anesthesiology Research Laboratories, Renmin Hospital of Wuhan University, Wuhan, P. R. China.

INTRODUCTION: There is emerging interest in the potential cardioprotective effects of inhalation anesthetics, but its application is limited. ${ }^{1}$ Other studies suggest propofol offers cardioprotection when doses higher than those conventionally used, are applied. ${ }^{2,3}$ The purpose of this study was to determine the safety and efficacy of the transient application of propofol cardioprotection in a dose response manner in the setting of aortocoronary bypass (ACBP) surgery.

METHODS: Following institutional approval, 29 patients with normal ejection fraction scheduled for ACBP surgery were randomized to receive isoflurane $1-3.5 \%$ (group-I), propofol $0.06 \mathrm{mg} / \mathrm{kg} / \mathrm{min}$ (group-P), or propofol $0.06 \mathrm{mg} / \mathrm{kg} / \mathrm{min}$, then $0.12 \mathrm{mg} / \mathrm{kg} / \mathrm{min} 10 \mathrm{~min}$ prior to, during and for $15 \mathrm{~min}$ following ACC (group-HiP) after anesthetic induction with midazolam and fentanyl. Central venous blood was sampled Pre-CPB, 8, 24 and 48 hours post-CPB for the measurement of cardiac troponin $\mathrm{T}$ and creatine kinase (CK-MB) (enzyme immunoassay) and plasma levels of malondialdehyde, a marker of lipid peroxidation. Perioperative hemodynamics were measured up to 24 hours postoperatively. Values for Troponin T, CK-MB and malondialdehyde A were corrected for hemodilution. $\mathrm{P}<0.05$ was considered significant.

RESULTS: Patients receiving high dose propofol had significantly decreased oxidant stress, lower indices of myocardial injury, reduced post-operative inotropic requirements and shorter ICU stay compared to those receiving low dose propofol or isoflurane maintenance anesthesia during cardiopulmonary bypass. The novel application of high dose propofol, around the time of ACC, was not associated with increased of hypotension or postoperative myocardial dysfunction.

CONCLUSION: Transient application of propofol in a higher than conventional dose attenuates postoperative myocardial cellular damage and preserves myocardial function in ACBP patients with normal ejection fraction, without compromising patient safety. Our findings will be applied in diabetic patients where signal transduction pathways for ischemic/pharmacologic preconditioning are impaired.

\begin{tabular}{|l|c|c|c|}
\hline Group & Isoflurane & Low Propofol & High Propofol \\
\hline Age (yr) & $61 \pm 3$ & $62 \pm 3$ & $59 \pm 5$ \\
Pre-op LVEF (\%) & $53 \pm 4$ & $55 \pm 3$ & $54 \pm 3$ \\
ACC (min) & $79 \pm 11$ & $87 \pm 13$ & $82 \pm 13$ \\
Inotropy > 30 min & $5 / 9$ & $3 / 10$ & $1 / 10^{*}$ \\
Time to Extubation (hr) & $8.6 \pm 2.3$ & $8.2 \pm 1.7$ & $7.1 \pm 2.8$ \\
Length ICU Stay (hr) & $48 \pm 3$ & $46 \pm 4$ & $37 \pm 3^{*}$ \\
\hline
\end{tabular}

$* \mathrm{p}<0.05$ vs isoflurane

\section{REFERENCES}

1. Am J Physiol Heart Circ Physiol 2004; 286:H1603-1607

2. Can J Physiol Pharmacol 2003; 81:14-21

3. Can J Anesth1999; 46:641-8 